\title{
Analysis of the degree of acceptance of illness among older adults living in a nursing home undergoing rehabilitation - an observational study
}

This article was published in the following Dove Press journal:

Clinical Interventions in Aging

\author{
Joanna Kowalska' \\ Justyna Mazurek ${ }^{2}$ \\ Joanna Rymaszewska ${ }^{3}$ \\ 'Department of Physiotherapy, University \\ School of Physical Education in Wroclaw, \\ Wroclaw, Poland; ${ }^{2}$ Department and \\ Division of Medical Rehabilitation, \\ Wroclaw Medical University, Wroclaw, \\ Poland; ${ }^{3}$ Department of Psychiatry, \\ Wroclaw Medical University, Wroclaw, \\ Poland
}

Introduction: The factors that influence the rehabilitation process among older adults remain unclear. The aim of the study was to assess the acceptance of illness and related factors (socio-demographic data, cognitive status, depression symptoms and functional status) among patients living in a nursing home who are undergoing rehabilitation.

Sample and methods: A total of 119 elderly patients were examined, of whom 96 were included in the research project. All participants were assessed using the following tests: Mini Mental State Examination, Acceptance of Illness Scale, Geriatric Depression Scale and Barthel Index. Tests were conducted at two time points, the first upon admission to the ward and the second after 3 months of regular rehabilitation.

Results: The study group showed relatively low scores for illness acceptance. After 3 months of rehabilitation, the acceptance of illness had significantly improved, but still remained at a low level. The results showed a relationship between acceptance of illness and patients' depression symptoms, functional status and cognitive status.

Conclusions: The results suggest that assessment of the acceptance of illness among patients living in Nursing Home is important during treatment and rehabilitation process; however, further studies are necessary.

Keywords: older adults, nursing home, rehabilitation, acceptance of illness, depression symptoms, cognitive status

\section{Introduction}

Disability among older adults is often the result of involutive changes that progress with age. These changes and the ensuing injuries, as well as chronic illnesses and their consequences, often cause a decrease in functional capacity to a level that prevents them from independently performing activities of daily living, making them reliant on the help of others, in addition to requiring rehabilitation. The occurrence of multiple morbidities, together with limitations in compensatory and adaptive mechanisms, hinders the course of treatment and rehabilitation required to adapt to a new situation, namely their illness. This is an intricate process which can continue until the end of the patient's life. ${ }^{1}$

The patient's level of acceptance of illness has a significant impact on their adaptation to the limitations related to their illness and disability, which is associated with many clinical and sociodemographic factors. ${ }^{2,3}$ On the one hand, lack of acceptance of the illness causes a great sense of mental discomfort and hinders adaptability, while on the other hand, greater acceptance of a given illness is
Correspondence: Joanna Kowalska Department of Physiotherapy, University School of Physical Education in Wroclaw, Paderewskiego 35 Street, Wroclaw 5I-6I2, Poland

Tel +4 87I 3473522

Fax $+487 \mid 347308$ I

Email joanna.kowalska@awf.wroc.pl 
associated with a reduced severity of negative reactions and emotions associated with the illness itself, as well as the associated comprehensive treatment and care. Additionally, accepting the illness may act as an element which activates the patient. For this reason, assessing the degree of acceptance is of significant importance in the holistic therapy of many illnesses, especially those of a chronic nature. ${ }^{3}$

The behaviors and reactions of people living with an illness may differ. They depend on several factors related to the illness itself, as well as the individual's predispositions, personal resources and external resources (eg, support from relatives). ${ }^{1}$

The available research indicates poor adaptation to illness among older patients, who have lower adaptation abilities when compared to younger people,,${ }^{3,4}$ particularly among patients under institutional care. ${ }^{2,5,6}$

Numerous studies have confirmed that greater acceptance of illness and disability is related to better adaptation to the illness and reduced discomfort. ${ }^{6-9}$ Acceptance of the illness and the associated restrictions does not mean resignation, but can instead help the patient regain self-esteem, a feeling of control over the situation and influence in the healing and rehabilitation processes, and can help them deal with negative emotions that arise during the illness. Furthermore, Painter emphasized that acceptance of an illness can act as an activating element, and the maintenance of physical activity promotes greater acceptance of the illness. ${ }^{10}$

The aim of the study was to analyze the degree of acceptance of illness among patients staying in a Nursing Home (NH) and undergoing regular rehabilitation, at two time points: at the time of admission to the ward (T1) and after 3 months of rehabilitation (T2). Specifically, we aimed to answer the following research questions:

1. Is there a relationship between the level of acceptance of illness in the older adults and their functional status before and after 3 months of rehabilitation?

2. What are the characteristics of patients with a low level of illness acceptance after 3 months of rehabilitation?

\section{Sample and method Studied group}

This study was conducted at a $\mathrm{NH}$ with a rehabilitation programme between 2015 and 2017. This observational study did not involve any interventions or experimental structures, and was carried out under the ethical and legal supervision of the Department of Physiotherapy of the
University School of Physical Education (6/11/2006). This study was conducted in accordance with the Helsinki Declaration.

The study group included patients who were consecutively admitted for rehabilitation, and who met the following inclusion criteria: voluntary written informed consent for participation in the study, aged over 60 years, satisfactory cognitive function status (MMSE $>15$ ), and systematic participation in a rehabilitation program for a period of 3 months. The exclusion criteria were as follows: patient refusal at any stage of the study, aphasia, shorter than 3 months stay in the center, inability to perform a cognitive function test or an unsatisfactory result and participation in any other additional forms of therapy (eg, occupational therapy).

All patients took part in regular physiotherapy of moderate intensity with a defined frequency and duration (Monday to Friday for 60 mins per day, of which 30 mins consisted of individual work adapted to the patient's functional status, and the remaining $30 \mathrm{mins}$ involved workouts using equipment and exercises to improve gait).

Participants were informed about the purpose of the study, the rules for participation and the possibility to withdraw at any stage of the study without consequences.

A total of 119 patients were examined, of whom 96 were included in the study (Figure 1).

The characteristics of the patients are presented in Table 1.

\section{Measurement tools}

All sociodemographic and clinical data were collected from the patients' medical files and during evaluations, which are routinely conducted by nurses upon admission to the NH.

The patients' cognitive function was assessed using the Mini Mental State Examination (MMSE) scale. The MMSE was developed to examine individuals with suspected dementia. It assesses orientation, memory, naming, reading comprehension, writing and constructional praxia (the ability to copy a complex graphic pattern). A Polish version of the MMSE scale, developed by Stańczak, has been confirmed to be highly accurate and reliable (Cronbach's alpha coefficient of 0.88 for a clinical trial and 0.82 for healthy people). ${ }^{11}$ The results were calculated considering the age and education level of participants based on the formula published by Mungas et al, which was verified for the Polish population by Jóźwiak et al. ${ }^{12,13}$ Patients can score a maximum of 30 points. A result below 




Figure I Recruitment process for the study group.

Table I The characteristics of the patients $(\mathrm{N}=96)$

\begin{tabular}{|l|l|}
\hline Baseline Characteristics & $\%$ \\
\hline Gender & \\
Female & 81 \\
Male & 19 \\
\hline Age & \\
Mean (SD) & $78.5(8.2)$ \\
Range & $61-97$ \\
\hline Education & \\
Primary & 30 \\
Vocational & 26 \\
Secondary & 30 \\
Higher & 14 \\
\hline Marital status & \\
Single (widow(er), unmarried) & 73 \\
Married & 27 \\
\hline Family care & \\
Lack of care capacity & 24 \\
Incomplete & 53 \\
Full & 23 \\
\hline Diagnosis & \\
Fractura & 29 \\
Stroke & 53 \\
Chronic illness & 18 \\
\hline Number of comorbidities & $4.0(1.7)$ \\
Mean (SD) & \\
Range & \\
\hline
\end{tabular}

Abbreviation: SD, standard deviation.

24 points suggests dementia. In patients who achieved MMSE score above 15 points, ${ }^{14,15}$ the following scales were used: Acceptance of Illness Scale (AIS), Geriatric Depression Scale (GDS) and Barthel Index (BI).

The AIS scale is used to assess the degree of acceptance of the illness. The scale contains 8 questions focused on the consequences of poor health, specifically limitations caused by the illness, lack of self-sufficiency, a sense of dependence on others and lowered self-esteem. For every statement, the patient defines his/her present status using a 5-point Likert's scale (where 1 point indicates "strongly agree", and 5 points indicate "strongly disagree"). One point means negative illness adaptation and 5 points means illness acceptance. The respondent can achieve a score from 8 to 40 points. A low score indicates a lack of acceptance of the illness, while a high score indicates adaptation to the illness and the associated discomfort. Consistent with this, a low score means that the patient may have significant emotional distress related to the illness, while a high score signifies good acceptance of one's own health. The results are grouped into three point ranges: scores below 20 points represent "poor acceptance" of the illness, scores between 20 and 30 points represent "average acceptance" and scores greater than 30 points mean "very good acceptance" of the illness. The Cronbach's reliability index is 0.85 for studies which use the Polish version. ${ }^{9}$

The GDS is the most commonly used self-assessment screening scale of patients' well-being and quality of life. The short version contains 15 questions where the patient answers "yes" or "no". The assessment concerns the 2-week period immediately preceding the test. The GDS assesses the subject's mood, their subjective satisfaction with their quality of life and their mood and feelings of 
happiness, or lack thereof. A score between 0 and 5 points indicates no depression, while a score of 6 points and above indicates depression of increasing severity. The Cronbach's reliability coefficient of the GDS is 0.94 , and the sensitivity and specificity are $84 \%$ and $95 \%$, respectively. ${ }^{16,17}$

The BI is the most common method for assessing the functional status of elderly patients. The scale is completed by medical personnel who assess the patient's capacity to independently carry out basic activities of daily living (eating, personal hygiene, using the toilet alone, walking, dressing, etc.) based on observations. Scoring ranges from 0 to 100 , where 100 means full functional capacity, while a score below 20 indicates a severe condition and the need for $24 \mathrm{hrs}$ care. The psychometric properties of the BI scale are very good. ${ }^{18}$

The above tests were conducted at two time points: upon admission to the ward (T1: AIS 1, GDS 1, BI1 and MMSE1) and after 3 months of regular physiotherapy (T2: AIS 2, GDS 2, BI2 and MMSE2).

\section{Data analysis}

The characteristics of the study group were obtained using descriptive statistics, including the mean, standard deviation, minimum and maximum values, and, in the case of qualitative variables, numbers and percentages. The Shapiro-Wilk test was used to check for normal distribution of the data. Because the hypothesis of a normal distribution was rejected, non-parametric tests were used: a Wilcoxon test to compare two dependent groups and a Mann-Whitney test to compare two independent groups. For comparison of more than two groups, Kruskal-Wallis ANOVA was used. In the case of qualitative variables, chisquare $\left(\chi^{2}\right)$ test was used. To determine the strength of the relationship between two variables, Spearman's rank coefficient was used. The significance threshold was set at $p<0.05$.

\section{Results}

The mean AIS score in the studied group at the time of admission to the NH (AIS1) was $16.5( \pm 6.4)$. Over $69 \%$ of patients were characterized as having a low level of illness acceptance at this time point. The mean MMSE score at the time of admission to the NH (MMSE1) was 22.8 $( \pm 3.8)$ points. The initial functional status of participants (BI1) was $40.3( \pm 19.6)$, while the mean GDS1 score was $7.4( \pm 3.1)$. As many as $72 \%$ of patients had depressive symptoms.
The lowest levels of illness acceptance at the time of admission to the NH (AIS1) and after 3 months of rehabilitation (AIS2) were found in patients with dementia, mood disorders, severely impaired functional status and in patients whose families had declared a lack of care capacity. There were no statistically significant differences in other factors such as gender, diagnosis, education or marital status (Table 2).

After 3 months of systematic rehabilitation, a statistically significant improvement was obtained for all of the tested parameters (Table 3 ).

The number of patients with depressive symptoms decreased to $31 \%$ after 3 months of staying in the $\mathrm{NH}$ while undergoing rehabilitation. The number of people with a low degree of acceptance of illness also decreased after 3 months of rehabilitation, but was still recorded in $26 \%$ of patients.

Therefore, based on the final AIS score obtained after 3 months of rehabilitation, a comparative analysis was performed on 2 groups of patients: those with low acceptance of illness (AIS 2 score of 8-19 points; $n=25$ ), and those with high acceptance of illness (AIS 2 score of 31-40 points; $n=20$ ).

A comparative analysis showed statistically significant differences between groups for variables including: MMSE1, MMSE2, BI1, BI2, GDS1, GDS2, AIS 1 and the change in BI. Compared to the high AIS2 group, the group of patients with a low AIS2 score had a poorer cognitive status, symptoms of depression, worse functional status, low level of illness acceptance at the time of admission to the ward and the least improvement in functional status after 3 months of rehabilitation (Table 4).

The group of patients with a low AIS 2 score also included patients after a stroke and those with incomplete family care. There were no statistically significant differences between the groups in the remaining variables (gender, education and marital status) (Table 5).

The results of the correlation analysis showed a statistically significant negative relationship between AIS and GDS, significant positive correlations between AIS and MMSE and between AIS and BI, and a change in BI over 3 months (difference between BI2 and BI1) (Table 6).

\section{Discussion}

The acceptance of one's illness plays a key role in the ability of older adults to adapt to various types of health restrictions, that is, adjusting to a new way of life. Greater acceptance decreases the intensity of negative emotions related to the illness, and facilitates the acceptance of 
Table 2 The level of illness acceptance by patients at the initial and final assessments (Mann-Whitney test and Kruskal-Wallis test)

\begin{tabular}{|c|c|c|c|c|c|}
\hline & \multicolumn{5}{|c|}{ AIS results } \\
\hline & \multirow[t]{2}{*}{$\mathbf{n}$} & AISI & \multirow[t]{2}{*}{$p$} & AIS2 & \multirow[t]{2}{*}{$p$} \\
\hline & & Mean (SD) & & Mean (SD) & \\
\hline \multicolumn{6}{|l|}{ Gender } \\
\hline Female & 78 & $16.4(6.4)$ & 0.799 & $23.9(7.5)$ & 0.617 \\
\hline Male & 18 & I6.8 (6.6) & & $24.7(7.3)$ & \\
\hline \multicolumn{6}{|l|}{ Diagnosis } \\
\hline Fracture & 28 & $16.6(5.8)$ & & $25.3(8.3)$ & \\
\hline Stroke & 51 & $15.8(6.6)$ & 0.367 & $22.4(7.0)$ & 0.070 \\
\hline Chronic illness & 17 & I8.I (6.5) & & $26.9(6.1)$ & \\
\hline \multicolumn{6}{|l|}{ Education } \\
\hline Primary/vocational & 54 & $16.6(6.4)$ & 0.653 & $24.5(7.3)$ & 0.391 \\
\hline Secondary/higher & 42 & $16.2(6.4)$ & & $23.4(7.6)$ & \\
\hline \multicolumn{6}{|l|}{ Marital status } \\
\hline Single (widow(er), unmarried) & 70 & $16.5(6.1)$ & 0.791 & $23.9(7.2)$ & 0.710 \\
\hline Married & 26 & $16.5(7.2)$ & & $24.4(8.1)$ & \\
\hline \multicolumn{6}{|l|}{ Family care } \\
\hline Lack of care capacity & 23 & $14.9(5.9)$ & & $22.2(7.3)$ & \\
\hline Incomplete & 51 & I5.8 (5.8) & 0.050 & $23.1(7.7)$ & 0.010 \\
\hline Full & 22 & $16.9(7.3)$ & & $28.0(5.5)$ & \\
\hline \multicolumn{6}{|l|}{ State of cognitive function (MMSEI) } \\
\hline Dementia (MMSE <24) & 56 & $14.9(5.7)$ & 0.006 & $22.7(7.6)$ & 0.012 \\
\hline No Dementia (MMSE $\geq 24$ ) & 40 & $18.7(6.6)$ & & $26.0(6.7)$ & \\
\hline \multicolumn{6}{|l|}{ Mood (GDSI) } \\
\hline No depression GDS $\leq 5$ & 27 & $21.7(5.9)$ & 0.0001 & $28.7(7.2)$ & 0.0001 \\
\hline Depression GDS >5 & 69 & $14.4(5.3)$ & & $22.2(6.7)$ & \\
\hline \multicolumn{6}{|l|}{ Initial functional status (BII) } \\
\hline Severe $(0-20)$ & 21 & $12.6(4.3)$ & & $20.1(6.5)$ & \\
\hline Moderate $(2 \mid-85)$ & 75 & $17.5(6.4)$ & 0.001 & $25.1(7.3)$ & 0.005 \\
\hline Slight & 0 & - & & - & \\
\hline
\end{tabular}

Abbreviations: AISI, Acceptance of Illness Scale upon admission to the ward; AIS2, Acceptance of Illness Scale after 3 months; MMSEI, Mini Mental State Examination upon admission to the ward; GDSI, Geriatric Depression Scale upon admission to the ward; BII, Barthel Index upon admission to the ward.

illness-induced limitations. ${ }^{19}$ An important intervention during rehabilitation is helping patients with chronic illness accept their disabilities, learn how to cope and live with them, and adapt to the physical and psychosocial sequelae. $^{20}$

At present, there is little discussion in the literature of illness acceptance among residents living in NHs. Therefore, the aim of the study was to assess the acceptance of illness among older adult patients in a Polish NH who were undergoing rehabilitation.

The results of this study show that people living in $\mathrm{NH}$ have a low level of illness acceptance. This result is consistent with the findings of Cybulski et al, who showed that the level of illness acceptance is significantly lower among people living in a $\mathrm{NH}$ when compared to students of Universities of the Third Age. ${ }^{5}$

The mean AIS values obtained in our study are significantly lower than those of other authors. Our AIS result is closest to that obtained by Kupcewicz and Abrahamowicz in patients with acute chronic obstructive pulmonary illness (COPD) (19 points). ${ }^{21}$ A significantly higher level of illness acceptance was recorded by Kurpas et al among chronically ill people over 60 years of age (25.72 points). ${ }^{22}$ In a study by Uchmanowicz et al, the level of acceptance of COPD was 20.6 points in patients aged 65.8 years. $^{23}$ In patients with asthma, the illness 
Table 3 Mean values for the tested parameters in the initial and final assessments

\begin{tabular}{|l|l|l|l|l|l|l|l|}
\hline \multirow{2}{*}{ Variables } & \multicolumn{2}{l}{ Initial data } & \multicolumn{2}{l|}{ Final data } & \multirow{2}{*}{ Difference } & \multicolumn{2}{l|}{ Wilcoxon Test } \\
\cline { 2 - 5 } \cline { 7 - 9 } & Mean & SD & Mean & SD & & Z & P \\
\hline MMSE & 22.8 & 3.8 & 23.5 & 3.5 & 0.7 & 2.69 & 0.007 \\
BI & 40.3 & 19.6 & 64.2 & 19.4 & 23.9 & 8.39 & $<0.0001$ \\
GDS & 7.4 & 3.1 & 4.8 & 3.0 & -2.6 & 7.25 & $<0.0001$ \\
AIS & 16.5 & 6.4 & 24.0 & 7.4 & 7.5 & 8.20 & $<0.0001$ \\
\hline
\end{tabular}

Abbreviations: MMSE, Mini Mental State Examination; BI, Barthel Index; GDS, Geriatric Depression Scale; AIS, Acceptance of IIIness Scale.

Table 4 Comparison of selected factors between patients with a low or high level of illness acceptance after 3 months of rehabilitation

\begin{tabular}{|c|c|c|c|c|c|}
\hline & \multicolumn{4}{|c|}{ AIS results after 3 months (AIS 2) } & \multirow{3}{*}{\begin{tabular}{|l} 
Mann-Whitney Test \\
$p$
\end{tabular}} \\
\hline & \multicolumn{2}{|c|}{ Low (8-19 points) } & \multicolumn{2}{|c|}{ High ( 3 I-40 points) } & \\
\hline & $\mathbf{n}$ & Mean (SD) & $\mathbf{n}$ & Mean (SD) & \\
\hline Age & 25 & $78.4(9.1)$ & 20 & $77.0(7.2)$ & 0.4413 \\
\hline Number of comorbidities & 25 & $4.0(1.5)$ & 20 & $4.1(1.5)$ & 0.8337 \\
\hline MMSE I & 25 & $21.7(3.0)$ & 20 & $24.7(3.9)$ & 0.0067 \\
\hline MMSE 2 & 25 & $22.2(3.0)$ & 20 & $25.6(2.7)$ & 0.0007 \\
\hline $\mathrm{BI} \mathrm{I}$ & 25 & $32.4(20.3)$ & 20 & $51.0(17.7)$ & 0.0025 \\
\hline BI 2 & 25 & $49.4(19.6)$ & 20 & $81.0(12.9)$ & $<0.0000 \mathrm{I}$ \\
\hline GDS I & 25 & $9.2(2.8)$ & 20 & $4.4(1.9)$ & $<0.00001$ \\
\hline GDS 2 & 25 & $7.6(2.6)$ & 20 & $1.7(0.8)$ & $<0.0000$ I \\
\hline AIS I & 25 & $10.8(2.7)$ & 20 & $23.2(5.8)$ & $<0.00001$ \\
\hline Change in $\mathrm{BI}$ (BI2-BII) & 25 & $17.4(12.7)$ & 20 & $30.0(17.9)$ & 0.0151 \\
\hline
\end{tabular}

Abbreviations: MMSEI, Mini Mental State Examination upon admission to the ward; MMSE2, Mini Mental State Examination after 3 months; GDSI, Geriatric Depression Scale upon admission to the ward; GDS2, Geriatric Depression Scale after 3 months; BII, Barthel Index upon admission to the ward; BI2, Barthel Index after 3 months; AISI, Acceptance of Illness Scale upon admission to the ward; AIS2, Acceptance of Illness Scale after 3 months.

acceptance rate was as high as 29.4 points, while in patients undergoing dialysis due to renal failure it was 25 points. $^{24,25}$ Juczyński showed statistically significant differences in mean AIS values between different groups of patients, such as patients with chronic pain (18.46), men after myocardial infarction (22.14), dialysis patients (24), women with breast and uterus cancers (28.16) and patients with Graves-Basedow disease (28.48). ${ }^{9}$ The results of our research suggest a poorer quality of life and poorer psychological adaptation to illness of older adults residing in a NH when compared to the results of the studies mentioned above. This theory seems to be confirmed, in part, by the results of Kaczmarczyk, who showed a significantly lower mean value of illness acceptance (23.5) among older residents of a $\mathrm{NH}$ compared to older patients residing in a normal home environment (28.3). According to the author, the home environment is conducive to positive attitudes, enabling the maintenance of fitness and independence in the elderly. ${ }^{2}$
There were no statistically significant differences in AIS results with regard to gender, diagnosis, level of education and marital status. Similar results have been obtained by other researchers; ${ }^{1,5,26}$ however, the opposite was observed in a study by Marmurkowska-Michałowska et al among people affected by paranoid schizophrenia, in which the mean AIS values were lower in males. ${ }^{27}$ In a study by Kazimierska-Zajac et al, women showed poorer acceptance of their illness than men, and patients with higher education showed a higher degree of illness acceptance than those with vocational education. ${ }^{28}$ Furthermore, in a study by Nowicki et al, women found it harder to accept rectal cancer and living with a stomy. ${ }^{29}$ However, it is worth noting that in the present work, people with a poor family care situation had the lowest level of illness acceptance.

Illness acceptance is closely related to other psychological phenomena. In our study, we observed that $\mathrm{NH}$ residents with dementia, depression and a low functional status showed the lowest level of illness acceptance. 
Table 5 Comparison between patients with a low or high level of illness acceptance after 3 months of rehabilitation

\begin{tabular}{|c|c|c|c|c|c|}
\hline & \multicolumn{4}{|c|}{ AIS results after 3 months (AIS 2) } & \multirow{3}{*}{$\frac{\chi^{2} \text { test }}{p}$} \\
\hline & \multicolumn{2}{|c|}{ Low (8-19 points) $n=25$} & \multicolumn{2}{|c|}{ High ( $3 I-40$ points) $n=20$} & \\
\hline & $\mathbf{n}$ & $\%$ & $\mathbf{n}$ & $\%$ & \\
\hline Gender & & & & & 0.6669 \\
\hline Female & 21 & 56.76 & 16 & 43.24 & \\
\hline Male & 4 & 50.00 & 4 & 50.00 & \\
\hline Diagnosis & & & & & 0.0126 \\
\hline Fractura & 6 & 42.86 & 8 & 57.14 & \\
\hline Stroke & 17 & 77.27 & 5 & 22.73 & \\
\hline Chronic illness & 2 & 22.22 & 7 & 77.78 & \\
\hline Education & & & & & 0.7608 \\
\hline Primary and vocational & 13 & 56.52 & 10 & 43.48 & \\
\hline Secondary and higher & 12 & 54.55 & 10 & 45.45 & \\
\hline Marital status & & & & & 0.5328 \\
\hline Single (widow(er), unmarried) & 18 & 58.06 & 13 & 41.94 & \\
\hline Married & 7 & 50.00 & 7 & 50.00 & \\
\hline Family care & & & & & 0.0121 \\
\hline Lack of care capacity & 8 & 80.00 & 2 & 20.00 & \\
\hline Incomplete & 16 & 59.26 & II & 40.74 & \\
\hline Full & I & 12.50 & 7 & 87.50 & \\
\hline
\end{tabular}

Table 6 Results of the Spearman's rank correlation for selected pairs of variables in the studied group

\begin{tabular}{|l|l|l|}
\hline Pairs of variables & $\begin{array}{l}\text { rho } \\
\text { Spearman }\end{array}$ & $\boldsymbol{p}$ \\
\hline AIS I \& MMSE I & 0.25 & 0.0129 \\
AIS I \& MMSE 2 & 0.27 & 0.0066 \\
AIS I \& GDS I & -0.57 & $<0.000$ I \\
AIS I \& GDS 2 & $-0.5 I$ & $<0.000$ I \\
AIS I \& BI I & 0.31 & 0.0019 \\
AIS I \& BI 2 & 0.30 & 0.0026 \\
AIS I \& Change BI (BI2-BII) & 0.02 & 0.8094 \\
AIS 2 \& MMSE I & 0.25 & 0.0139 \\
AIS 2 \& MMSE 2 & 0.32 & 0.0013 \\
AIS 2 \& GDS I & -0.53 & $<0.000$ I \\
AIS 2 \& GDS I & -0.73 & $<0.000$ I \\
AIS 2 \& BI I & 0.31 & 0.0019 \\
AIS 2 \& BI 2 & 0.57 & $<0.0001$ \\
AIS 2 \& change BI (BI2-BII) & 0.32 & 0.0014 \\
\hline
\end{tabular}

Abbreviations: MMSEI, Mini Mental State Examination upon admission to the ward; MMSE2, Mini Mental State Examination after 3 months; GDSI, Geriatric Depression Scale upon admission to the ward; GDS2, Geriatric Depression Scale after 3 months; BII, Barthel Index upon admission to the ward; BI2, Barthel Index after 3 months; AISI, Acceptance of Illness Scale upon admission to the ward; AIS2, Acceptane of Illness Scale after 3 months.

Similarly, in the study by Uchmanowicz et al discussed earlier, illness acceptance was significantly correlated with the intensity of depressive symptoms. ${ }^{23}$ Kurpas et al confirmed that a higher level of illness acceptance generated a better quality of life, especially in the physical and

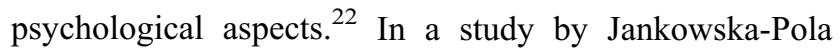
ńska et al, acceptance of an illness had a significant impact on perception of quality of life in patients with COPD, where the greater the acceptance, the higher the quality of life rating. ${ }^{30}$

After 3 months of rehabilitation, statistically significant improvement was observed in the values of all tested scales, including the level of illness acceptance; however, the overall score remained low (16.5 vs 24.0).

In the present study, we also noted that the degree of acceptance of illness is associated with many factors, such as the patient's functional status, mood level and level of cognitive function, as well as their diagnosis and the caretaking capacity of their family. This justifies the assessment of these variables, particularly prospectively, which can be an important element in the process of holistic medical care and non-medical care, including the comprehensive rehabilitation process. In particular, there was a statistically significant relationship between 
the degree of illness acceptance and their functional status and its change over time. Therefore, it seems necessary to include this type of evaluation in a larger number of clinical trials in order to further analyze and validate this factor and confirm the accuracy of interpretation of the results of the presented research tool. Health care providers should consider implementing an appropriate rehabilitation care procedure for older adults living in NHs, supplemented by a clinically validated and psychometrically sound assessment tool. This is imperative to help patients better psychologically adapt to their illness, and might even improve the survival rate of patients with chronic illness. ${ }^{20}$

Few limitations must be acknowledged. These include the diversity of the group regarding their reason for undertaking rehabilitation. The studies carried out were of a screening nature and the findings obtained were not unequivocal with that of a medical diagnosis being made. The study participants were recruited from a single $\mathrm{NH}$, which may limit the generalisability of the findings. Future studies should use larger samples and use random or stratified sampling methods of data collection in order to improve the representativeness of the sample.

\section{Conclusions}

1. Residents of the NH had a low level of illness acceptance at the beginning of rehabilitation process.

2. After 3 months of rehabilitation, the level of illness acceptance had significantly improved, but still remained low, especially among patients after a stroke, with incomplete family care, with lower MMSE scores, symptoms of depression, poor functional status and those who showed the least improvement in functional status.

3. In the studied group of older adults, a significant relationship was observed between the level of acceptance of illness and the functional status of patients at the beginning of rehabilitation and after 3 months. The higher the degree of acceptance of illness in respondents, the greater the recorded improvement in functional status.

4. The results suggest that it is important to assess illness acceptance among patients living in a $\mathrm{NH}$ during the rehabilitation process; however, further studies are necessary.

\section{Acknowledgments}

The authors would like to thank Ms Honorata Turkiewicz for preparing data for statistical analysis.

\section{Author contributions}

JK was responsible for study conception and design, data collection, analysis and interpretation of data, writing, drafting and revising the article. JM was responsible for interpretation of data, writing the discussion, drafting and revising the article. JR was responsible for interpretation of data and drafting the article. All the authors gave final approval of the version to be published; and agree to be accountable for all aspects of the work.

\section{Disclosure}

The authors report no conflicts of interest in this work.

\section{References}

1. Rolka H, Pilecka E, Kowalewska B, et al. Acceptance evaluation of disease and quality of life of patients with pacemaker. Piel Zdr Publ. 2012;2(3):183-192.

2. Kaczmarczyk M. The level of acceptance of illness among elderly people living in different environments. Stud Med. 2008;12:29-33.

3. Mazurek J, Lurbiecki J. Acceptance of illness scale and its clinical impact. Pol Merk Lek. 2014;36(212):106-108.

4. Niedzielski A, Humeniuk E, Błaziak P, Fedoruk D. Stopień akceptacji choroby w wybranych chorobach przewlekłych. Wiad Lek. 2007;60(5-6):224-227.

5. Cybulski M, Cybulski Ł, Krajewska-Kułak E, Cwalina U. Illness acceptance, pain perception and expectations for physicians of elderly in Poland. BMC Geriatr. 2017;17(1):46. doi:10.1186/ s12877-017-0441-4

6. Kowalska J, Wolny K, Kobylańska M, Wójcik B. The degree of acceptance of illness and functional status among elderly people staying in the rehabilitation centre. Geriatria. 2015;9:3-9.

7. Jasielska A. Emotion regulation as an example of emotional functioning in age from 60 to 85 years. Gerontol Pol. 2011;19 (2):112-118.

8. Maciejuk-Płońska A, Nasiłowska-Barud A, Kostecka P, Fedorovich V. Psychological aspects of rehabilitation of the elderly people after femoral neck fracture. Pol Merk Lek. 2012;32 (187):79-81.

9. Juczyński Z. Narzędzia pomiaru $w$ promocji i psychologii zdrowia, drugie wydanie. Warszawa: Pracownia Testów Psychologicznych Polskiego Towarzystwa Psychologicznego; 2011.

10. Painter P. Physical functioning in end-stage renal disease patients: update 2005. Hemodial Int. 2005;9:218-235. doi:10.1111/j.14927535.2005.01136.x

11. Stańczak J. MMSE Polska normalizacja. Warszawa. Polska: Pracownia Testów Psychologicznych Polskiego Towarzystwa Psychologicznego; 2010.

12. Mungas D, Marshall SC, Weldon W, Reed BR. Age and education correction of mini mental state examination for English- and Spanish-speaking elderly. Neurology. 1996;46:700-706. doi:10.1212/WNL.46.3.700

13. Jóźwiak A, Wiśniewska J, Wieczorkowska-Tobis K. Zaburzenia pamięci u osób starszych oceniane testem Mini Mental Scale. Gerontol Pol. 2000;1:46-50. 
14. McGivney SA, Mulvihill M, Taylor B. Validating the GDS depression screen in the nursing home. J Am Geriatr Soc. 1994;42 (5):490-492. doi:10.1111/j.1532-5415.1994.tb04969.x

15. Snowdon J, Lane F. Use of the geriatric depression scale by nurses. Aging Ment Health. 1999;3(3):227-234. doi:10.1080/13607869956181

16. Albiński R, Kleszczewska-Albińska A, Bedyńska S. Geriatric depression scale (GDS). Validity and reliability of different versions of the scale-review. Pol Psychiatr. 2011;XLV(4):555-562.

17. Yesavage JA, Brink TL, Rose TL, et al. Development and validation of a geriatric depression screening scale: a preliminary report. J Psychiatr Res. 1983;17:37-49. doi:10.1016/0022-3956(82)90033-4

18. Mahoney F, Barthel DW. Functional evaluation: the Barthel index. Md State Med J. 1965;14:61.

19. Telford K, Kralik D, Koch T. Acceptance and denial: implications for people adapting to chronic illness: literature review. J Adv Nurs. 2006;55:457-464. doi:10.1111/j.1365-2648.2006.03942.x

20. Chiu SY, Livneh H, Tsao LL, Tsai TY. Acceptance of disability and its predictors among stroke patients in Taiwan. BMC Neurol. 2013;13:175. doi:10.1186/1471-2377-13-175

21. Kupcewicz E, Abramowicz A. Assessment of quality of life in chronic obstructive pulmonary disease patients. Hyg Publ Health. 2014;49:805-812.

22. Kurpas D, Mroczek B, Bielska D. The correlation between quality of life, acceptance of illness and health behaviors of advanced age patients. Arch Gerontol Geriatr. 2013;56:448-456. doi:10.1016/j.archger.2012.12.010

23. Uchmanowicz I, Jankowska-Polańska B, Motowidlo U, Uchmanowicz B, Chabowski M. Assessment of illness acceptance by patients with COPD and the prevalence of depression and anxiety in COPD. Int J Chron Obstruct Pulmon Dis. 2016;11:963-970. doi:10.2147/COPD.17
24. Rusin-Pawelek E, Uchmanowicz I, Jankowska-Polańska B, Panaszek B, Fal AM. Acceptance of illness of patients with bronchial asthma and asthma control. Alergologia Info. 2012;7:61-67.

25. Kurowska I, Kasprzyk A. Disease acceptance and the ways of coping with stress in patients on dialysis. Psychiatr Psychol Klin. 2013;13:99-107.

26. Bąk E, Marcisz C, Krzemińska S, Dobrzyn-Matusiak D, Foltyn A, Drosdzol-Cop A. Relationships of sexual dysfunction with depression and acceptance of illness in women and men with type 2 diabetes mellitus. Int J Environ Res Public Health. 2017;14(9):1073. doi:10.3390/ijerph14091073

27. Marmurkowska-Michałowska H, Dubas-Slemp A, Kozak A, Dolecki W, Kochański A. Przystosowanie do choroby w grupie osób z rozpoznaniem schizofrenii paranoidalnej - doniesienie wstępne. Badania nad schizofrenia. 2004;5:324-329.

28. Kazimierska-Zając M, Dymarek R, Rosińczuk J. Quality of life and the degree of disease acceptance in patients with spinocerebellar ataxia. Jnnn. 2018;7(1):12-21.

29. Nowicki A, Marciniak J, Farbika P, Banaszkiewicz Z. Satisfaction with life and disease acceptance by patients with a stomy related to surgical treatment of the rectal cancer - determinants of quality of life? Pol Prz Chir. 2015;87(9):434-442.

30. Jankowska-Polańska B, Kasprzyk M, Chudiak A, Uchmanowicz I. Effect of disease acceptance on quality of life in patients with chronic obstructive pulmonary disease (COPD). Pneumon Alergol Pol. 2016;84(1):3-10. doi:10.5603/PiAP. a2015.0079
Clinical Interventions in Aging

\section{Publish your work in this journal}

Clinical Interventions in Aging is an international, peer-reviewed journal focusing on evidence-based reports on the value or lack thereof of treatments intended to prevent or delay the onset of maladaptive correlates of aging in human beings. This journal is indexed on PubMed Central, MedLine, CAS, Scopus and the Elsevier
Bibliographic databases. The manuscript management system is completely online and includes a very quick and fair peer-review system, which is all easy to use. Visit http://www.dovepress.com/ testimonials.php to read real quotes from published authors. 